\title{
SUBJETIVIDADES
}

\section{Estudos Teóricos}

\author{
e-ISSN: 2359-0777
}

\section{SEXUALIDADE, CORPO E PSICANÁLISE}

\author{
Sexuality, Body, and Psychoanalysis
}

Sexualidad, Cuerpo y Psicoanálisis

\section{Sexualité, Corps et Psychanalyse}

10.5020/23590777.rs.v20i3.e8756

\section{Shimênia Vieira de Oliveira Cruz 9 \\ Psicanalista. Doutora em Psicologia pela Universidade Federal da Bahia.}

\author{
Aléssia Silva Fontenelle 9 \\ Doutora em Teoria Psicanalítica pela Universidade Federal do Rio de Janeiro. Psicanalista, membro da Escola Brasileira de Psicanálise e da AMP (Associação \\ Mundial de Psicanálise). Professora Adjunta II do curso de Psicologia da Universidade Federal do Vale do São Francisco, coordenadora do NuPSam.
}

\section{Resumo}

O presente trabalho objetiva promover uma reflexão no campo da sexualidade por meio da abordagem de alguns conceitos fundamentais para a psicanálise. O modo como esta delimita conceitualmente o corpo e o gozo nos auxilia nessa tarefa de articular as noções contemporâneas de sexualidade e gênero. A metodologia utilizada para a elaboração deste artigo se deu a partir do estudo sistemático de produções do Campo Lacaniano, que acontecem uma vez por semana no NuPSaM (Núcleo de Psicanálise e Saúde Mental) da Universidade Federal do Vale do São Francisco. O texto, que ora se apresenta, foi elaborado a partir da I Jornada de Psicanálise da Univasf. Sabemos, com Freud, que a sexualidade está para além do instinto sexual, promovendo uma ruptura em relação aos órgãos genitais em si. Há, nesse sentido, uma função corpórea mais abrangente, ligada às pulsões, que visam a objetos que nada têm a ver com uma finalidade reprodutiva. Tal perspectiva é atravessada pela impossibilidade da relação sexual, pelo que não cessa de não se escrever. Assim, o que está em questão são as posições de gozo e a distinção do gozo fálico do gozo Outro, gozo esse suplementar e relativo ao enigma do feminino. Com isso, qualquer um pode se alojar numa ou outra posição (gozo suplementar ou fálico) frente ao real do sexo. Ao introduzir a pluralização do gozo, a sexualidade passa a ser abordada a partir da lógica, do singular. O gênero se aproxima da questão do ser, refere-se ao que desperta, em cada sujeito, a questão do que deseja e de quem deseja.

Palavras-chave: corpo; sexualidade; gozo; psicanálise; gênero.

\section{Abstract}

The present work aims to promote a reflection in the field of sexuality through the approach of some fundamental concepts for psychoanalysis. How it conceptually delimits the body and enjoyment assist us in this task of articulating contemporary notions of sexuality and gender. The methodology used to prepare this article was based on the systematic study of productions from Campo Lacaniano, which take place once a week at NuPSaM (Nucleus of Psychoanalysis and Mental Health) at the Federal University of Vale do São Francisco. The text, which is now presented, was elaborated from the 1st Seminar of Psychoanalysis of Univasf. We know, with Freud, that sexuality is beyond the sexual instinct, promoting a rupture about genitals organs themselves. In this sense, there is a more comprehensive bodily function, linked to drives, which aim at objects that have nothing to do with a reproductive purpose. Such a perspective is crossed by the impossibility of sexual intercourse, so it does not cease not to write. Thus, what is at issue are the positions of enjoyment and the distinction of phallic enjoyment from Other enjoyment, a enjoyment that is supplementary and related to the enigma of the feminine. With this, anyone can stay in one or another position (phallic or supplementary enjoyment) in front of the real sex. When introducing the pluralization of enjoyment, sexuality is approached from the logic, from the singular. Gender comes closer to the question of being, refers to what awakens, 
in each subject, the question of what he wants and whom he wants.

Keywords: body; sexuality; enjoyment; psychoanalysis; gender.

\section{Resumen}

Este trabajo tiene el objetivo de promover una reflexión en el campo de la sexualidad por medio del enfoque de algunos conceptos fundamentales para el psicoanálisis. El modo como esta delimita conceptualmente el cuerpo y el gozo nos ayuda en la tarea de articular las nociones contemporáneas de sexualidad y género. La metodología utilizada para la elaboración de este artículo fue a partir del estudio sistemático de producciones del Campo Lacaniano, que ocurren una vez a la semana en NuPSaM (Núcleo de Psicoanálisis y Salud Mental) de la Universidade Federal do Vale do São Francisco. El texto fue elaborado a partir de la I Jornada de Psicoanálisis de la Univasf. Sabemos, con Freud, que la sexualidad está para allá del instinto sexual, fomentando una ruptura en relación a los órganos genitales. Hay, en este sentido, una función más amplia, ligada a las pulsiones, que no tienen nada que ver con una finalidad reproductiva. Esta perspectiva es traspasada por la imposibilidad de la relación sexual, por lo que no cesa de no escribir. Así, lo que está en cuestión son las posiciones de gozo y la distinción del gozo fálico del gozo Otro, gozo este suplementar y relativo al enigma del femenino. Con esto, cualquiera puede alojar en una u otra posición (gozo suplementar o fálico) ante al sexo real. Al introducir la pluralización del gozo, la sexualidad pasa a ser enfocada a partir de la lógica, del singular. El género se acerca de la cuestión del ser, se refiere a lo que despierta, en cada sujeto, la cuestión de lo desea y de quién desea.

Palabras clave: cuerpo; sexualidad; gozo; psicoanálisis; género.

\section{Résumé}

Le présent travail vise à promouvoir une réflexion dans le domaine de la sexualité à travers l'approche de certains concepts fondamentaux de la psychanalyse. La manière dont elle délimite de façon conceptuelle le corps et la jouissance nous assiste dans la tâche d'articulation des notions contemporaines de sexualité et de genre. La méthodologie utilisée dans cet article était basée sur l'étude systématique des productions de Campo Lacaniano, qui ont lieu une fois par semaine au NuPSaM (Centre de Psychanalyse et de Santé Mentale) de l'Université Fédérale du Vale do São Francisco, Brésil. Le texte, qui est maintenant présenté, a été élaboré à partir de laler journée de Psychanalyse à l'Univasf. Il est fait notoire que, pour Freud, la sexualité est au-delà de l'instinct sexuel, en favorisant une rupture par rapport aux organes génitaux eux-mêmes. En ce sens, il y a une fonction corporelle plus complète, liée à des pulsions, qui visent des objets qui n'ont rien à voir avec un but reproductif. Une telle perspective est traversée par l'impossibilité de la relation sexuelle. Ainsi, ce qui est le cerne sont des positions de jouissance et la distinction entre la jouissance phallique et la jouissance Autre. Cette dernière jouissance est complémentaire et liée à l'énigme du féminin. Donc, quelqu'un peut être dans n'importe quelle position (jouissance Autre ou phallique) en face au réel du sexe. Quand la pluralisation de la jouissance est introduite, la sexualité est, maintenant, abordée à partir de la logique, du singulier. Le genre s'approche de la question de l'être, fait rapport à ce qui éveille, dans chaque sujet, la question de ce que l'on veut et de qui le veut.

Mots-clés : corps ; sexualité ; jouissance ; psychanalyse ; genre.

O presente trabalho objetiva promover uma reflexão no campo da sexualidade por meio da abordagem de alguns conceitos fundamentais para a psicanálise. O modo como esta delimita conceitualmente o corpo e o gozo nos auxilia nessa tarefa de articular as noções contemporâneas de sexualidade e gênero.

A metodologia utilizada para a elaboração deste artigo se deu a partir do estudo sistemático de produções do Campo Lacaniano, estudos teóricos acontecem uma vez por semana no NuPSaM (Núcleo de Psicanálise e Saúde Mental) da Universidade Federal do Vale do São Francisco. A partir da definição da temática e da bibliografia a ser estudada, ocorrem os encontros, nos quais são realizadas as discussões referentes aos temas, as quais culminam na produção de textos originais que são apresentados nas jornadas pelos participantes do núcleo, obedecendo às regras metodológicas e de argumentação teóricoconceitual estabelecida pelo núcleo de estudos.

O texto que ora se apresenta foi elaborado a partir de produções apresentadas na I Jornada de Psicanálise da Univasf, na qual o tema foi circunscrito em gênero e sexualidades.

Para tanto, foram utilizadas referências clássicas e atuais, com o intuito de problematizar, de forma estruturada, a questão que se impõe sobre os modos de fazer laço na contemporaneidade, bem como sobre os diversos estereótipos configurados a 
partir de "categorias" de gênero, por meio das quais os sujeitos têm delineado sua orientação sexual, mais especificamente, no que tange à sua organização psíquica.

Para a psicanálise, a sexualidade está para além do instinto sexual. Ela promove uma ruptura em relação aos órgãos genitais em si. Há, desse modo, uma função corpórea mais abrangente, ligada às pulsões, que visa primordialmente a satisfação, em detrimento do objeto. Como já apontava Freud (1917/1996b), no ser humano, a sexualidade não é regida pelo instinto, mas pelas pulsões, as quais tendem a objetos que nada têm a ver com uma finalidade reprodutiva.

Pretendendo questionar a premissa de que a biologia é o destino, retomamos a concepção de Butler (2003) de que tanto o sexo quanto o gênero referem-se a significados culturais assumidos pelo corpo, ou seja, eles são cultural e socialmente construídos. Nessa perspectiva, há uma extrusão da ideia de estruturas que nos parecem tão naturalizadas, como o sexo, o corpo e as diferenças entre macho e fêmea, circunscritas na associação de um corpo de homem ou de mulher. A autora contrapõe a ideia de que o sexo estaria na dimensão da natureza. Para ela, sexo e gênero são construções sociais.

No campo das ciências sociais, como nos assinala Leite (2003), temos a clássica diferenciação entre sexo e gênero. Nesta, o eixo feminino/masculino depende de uma autoimagem psicológica e de uma autodesignação feita pela criança como sendo de um sexo ou de outro. Uma nomeação altamente influenciada pela atribuição sexual recebida do meio.

Por sua vez, "para a biologia, a sexualidade humana se resume à distinção entre dois sexos, definidos a partir dos atributos anatômicos e do código genético. No campo das ciências biológicas, portanto, a sexualidade é um fato e não uma questão" (Dias, 2007, p. 63). O estabelecimento dessa dita verdade sobre a sexualidade humana também se evidencia em outras áreas de saber.

Contudo a psicanálise parte da premissa de que o corpo não está localizado no campo natural, biologicamente determinado. Conforme afirmamos, ele não é um fato, um dado, mas uma construção, uma inscrição a ser efetivada no aparelho psíquico. Para Freud (1923/1996c), essa inscrição do corpo nunca é realizada totalmente, ocorrendo apenas parcialmente. Há sempre um excesso, um resto que não se inscreve e não cessa de não se escrever, e, com isso, causa efeitos. Podemos afirmar que o corpo pulsional revela o atravessamento que ocorre no sujeito pelos efeitos de sua inscrição na linguagem.

A temática da sexualidade humana nos remete, essencialmente, à dimensão do corpo pulsional, não ao corpo falado ou ao corpo que adquire capacidade de falar, mas, antes, ao corpo que goza e que o ser humano jamais alcançará enquanto ser falante. De fato, Lacan cria o neologismo parlêtre [falasser] para substituir a noção de "sujeito" pelo de ser de fala, incluindo nesse termo sujeito e substância gozante. Aborda, assim, a vertente do gozo e sua implicação com o significante, isto é, como marca contingente do impacto originário entre linguagem e corpo. Desde então, o corpo se configura como uma superfície de inscrição, não de sentido, mas de gozo (Lacan, 1972/1985). Trata-se, portanto, de uma escrita que serve ao gozo, àquilo que o ser falante, o falasser, tem de mais singular.

Posto que não é esse corpo em si que determinará o modo a partir do qual um sujeito goza, de que corpo podemos falar quando formulamos a questão sobre a sexualidade?

\section{O Corpo e a Diferença Sexual: Breves Considerações em Psicanálise}

Para a psicanálise, a sexualidade tem uma função estrutural no processo de constituição da identidade do sujeito humano. A hipótese lacaniana apontada no Seminário 20: Mais, ainda (Lacan, 1972/1985), de que o inconsciente tem incidência sobre o corpo se inicia com Freud, ao demonstrar no sintoma histérico que a linguagem recorta o corpo sem que isso nada tenha a ver com a anatomia. Ao propor a etiologia sexual dos sintomas histéricos no final do séc. XIX, Freud causa uma ruptura com o determinismo biológico, demonstrando que a principal característica da sexualidade humana é ser polimorfa, ou seja, não ter um objeto sexual predeterminado geneticamente (o objeto de satisfação da pulsão sexual pode ser qualquer um).

Freud (1917/1996b) vai mostrar que, em nossa espécie, a sexualidade não é regida pelo instinto, mas pelas pulsões, as quais visam objetos que nada têm a ver com uma finalidade reprodutiva. Ele descreve a sexualidade infantil como perversa polimorfa, ou seja, como uma espécie de amostra de todas as formas de perversão: “[...] a observação mostra facilmente que raras vezes um ou outro traço de perversão está ausente da vida sexual de pessoas normais". (p. 326)

Assim, constatamos que, para o humano, ser homem e ser mulher têm a ver com o que se nomeia por homem e mulher numa determinada cultura. A sexualidade humana não é da ordem da natureza, mas um efeito de fala, resultado das operações com os significantes impostos pela linguagem e pela cultura.

Para a psicanálise, a sexualidade do ser de linguagem - do falasser, como denominou Lacan - não é um processo natural. A linguagem opera uma desnaturação do sexo: diferentemente dos animais, não possuímos um instinto sexual que visa um objeto natural (o sexo oposto) com a finalidade única de reprodução da espécie. Na natureza, tampouco existe sofrimento ligado ao sexo, porque cada indivíduo segue um conjunto de condutas universais e predeterminadas (o cio), que o guiam sem hesitação ao encontro do objeto sexual (Teixeira, M. C, 2013).

Outro ponto para situar no campo da psicanálise a problemática do corpo e da sexualidade é que é necessário dizer que o corpo é feito para gozar. Logo, o corpo que interessa à psicanálise se distingue do organismo e se define pela relação com o 
significante. Apoiados nessa formulação do inconsciente tomado como aparelho de gozo, podemos capturar o corpo através do sintoma, que dá testemunho de uma "anatomia significante". Tal como Lacan nos esclarece no Seminário 20:

A realidade é abordada com os aparelhos do gozo [grifo do autor]. Se é que podemos convir que, aparelho, não há outro senão a linguagem. É assim que, no ser falante, o gozo é aparelhado. [...] A partir daí, essa linguagem se esclarece sem dúvida por se colocar como aparelho de gozo. (Lacan, 1972/1985, p. 75)

O corpo, para a psicanálise, é pulsional, regido pela libido, visando basicamente a satisfação. Para a psicanálise, o corpo não é a carne, é o corpo pulsional que trabalha em nome da satisfação. Esse corpo se distingue do organismo, cuja função primordial é a perpetuação da espécie e a procriação. Ao corpo pulsional não interessa a finalidade biológica da reprodução, pois a sexualidade humana nada mais tem de natural, uma vez que se inscreve no campo simbólico, tendo, desse modo, arrancado o corpo pulsional da sua função biológica; desnaturalizando-o pela incidência do significante.

Lacan, inicialmente, situa o corpo no campo da imagem especular, fazendo jus à importância dada por Freud ao campo escópico, isto é, ao objeto olhar para, rapidamente, passar a primazia ao significante, privilegiando o objeto voz. Entretanto a grande contribuição feita por Lacan à teoria do corpo diz respeito à consistência deste nos três registros: imaginário, simbólico e real, atados pelo nó borromeu emprestado da topologia.

No registro imaginário, situa a imagem especular do corpo enquanto corpo narcísico. A consistência do corpo no imaginário é o próprio cordão que ata o nó. No registro simbólico, situa o corpo enquanto materialidade significante, enquanto corpo falante sustentado pela estrutura de linguagem, cuja anterioridade e exterioridade se presentificam no corpo simbólico, cuja consistência é o furo, o toro. No real, o corpo se situa enquanto gozo, corpo feito para gozar de si mesmo, cuja realidade pulsional tem como

O Real em Lacan é pensado como um resto impossível de simbolizar, e o Simbólico é o lugar do significante e da função paterna. O Imaginário é o lugar do primado do eu, da fusão com o corpo da mãe, por isso Lacan, que no início do seu percurso propusera-o no estágio do espelho, vai defendê-lo como lugar da relação dual com a imagem do semelhante. Apreende, assim, um espaço para localizar os fenômenos das ilusões do eu, da alienação, da captação e do engodo. (Souza, 2013, p.54)

No que concerne ao quarto termo para fazer o nó borromeano, a saber, o sintoma, poder-se-ia dizer que sintoma e corpo aí se equivalem. Para a psicanálise, o corpo pulsional é o corpo do ser falante, e seu modo de gozar situa-se, por um lado, na periferia; por outro lado, fora do corpo. Esse gozo localiza-se nas bordas, nos buracos do corpo, chamado por Freud de zonas erógenas. Simultaneamente, situa-se fora do corpo por meio de seus objetos que são separados do corpo, enumerados por Lacan em quatro: seio, fezes, voz e olhar.

Esse corpo afetado pelo significante, por um lado, sofre radicalmente os efeitos de mortificação de certo gozo do corpo biológico, pois jamais teremos, como nos lembra Lacan, a experiência do gozo do lírio ou da ostra que, sem dúvida, gozam por serem organismos vivos, porém como não falam. É desse gozo natural do vivo que o homem já nasce castrado pelo simples fato da sua entrada na linguagem, desnaturalizando esse gozo, situando-o de saída no campo da linguagem, no campo do simbólico, do inconsciente. Por outro lado, esse mesmo significante que mortifica o gozo, vivifica-o, dando-lhe essa nova realidade chamada pulsional.

Há uma passagem em Lacan em que define a pulsão de modo bastante peculiar: ““”As pulsões são, no corpo, o eco do fato de que há um dizer. Esse dizer, para que ressoe, para que consoe, [...] é preciso que o corpo lhe seja sensível. É um fato que ele o é". (Lacan, 1975-76/2007, p. 18). Essa consideração feita por Lacan não nos deixa esquecer que o corpo humano é o único corpo falante entre os seres vivos com a ressalva de que, biologicamente, esse corpo está aparelhado para falar se lhe é dado a chance. Nenhum outro corpo vivo, exposto às condições da fala, a ela responderia positivamente. Entretanto, se esse corpo está marcado biologicamente para responder a essa função da fala, de modo nenhum funciona instintivamente, como fazem outros animais nas suas naturais manifestações de comportamentos instintuais. É fato que o corpo está aparelhado para falar, porém dependerá de um dizer que venha nele fazer um furo, animando-o a falar.

Desde Freud (1895/1996a), ele já apontava para certa função do grito, que passava da pura necessidade para a tentativa de comunicar algo ao Outro diante de seu desamparo. Lacan (1968-1969/2008) indicava, de igual forma, que o grito servia para se fazer ouvir e para ser relatado a outro, e ressalta o interesse do bebê nas modulações que a voz adquire e ecoa, pontuando a curiosidade do bebê para os sons. Com isso, Lacan (1968-1969/2008) afirma que "desde a origem, a criança se alimenta tanto de palavras quanto de pão" (p. 192).

A lalação tem a ver com o gozo de alíngua, que ainda não é linguagem. Lacan (1977) denominou esse gozo, sem endereçamento ao Outro, alíngua. Essa é a língua particular e única para cada ser falante, falasser. A alíngua comporta a primeira entrada do sujeito no significante, anteriormente à fala e à linguagem. Significante este caracterizado por um nada querer 
dizer. Ela "é o inconsciente real, o inconsciente-alíngua" ([grifo do autor] Soler, 2012, p. 128), é (a) língua do inconsciente de cada um. Como Lacan aponta no Seminário 20, p. 198, "alíngua serve para coisas inteiramente diferentes da comunicação".

Ela se configura para além do objeto da necessidade, definida como "gozo próprio do sujeito" (Lefort, 1992, p. 07), e transmuta o encadeamento "necessidade-demanda-desejo" para "gozo-demanda-desejo", em que, para o falasser, o gozo é significante e o falo é o significado. Nisso, Lacan nos ensina que o gozo de alíngua se inscreve como gozo do UM antes do Outro.

Lacan define que o balbucio é S1, S1 sem S2, muitos S1, um "enxame de S1". Lefort (1992) aponta, a partir disso, que S1 sozinho, primordialmente, está situado no campo do gozo, ou seja, está fora dos efeitos de sentido.

Esses sons iniciais, primeiramente, são pura melodia, pura música. Em essência, um jogo de gozo que a criança pode produzir em resposta à demanda do Outro primordial, ou daquele que exerça essa função para o infans (Freud, 1895/1996a). A voz do Outro primordial, enigmática, revestida pela musicalidade de sua voz, incidirá diretamente no corpo do infans, fazendo-o advir por uma perda de seu ser e ex-sistindo como falante, falasser [parlêtre].

Considerando o conceito de falasser, Lacan nos ensina, no Seminário 20, que a linguagem não visa à comunicação, mas ao gozo, "o gozo de que depende essa outra satisfação, a que se baseia na linguagem (Lacan, 1972/1985, p.71). E, nesse sentido, entendendo assim alíngua, compreendemos que a linguagem é elocubração de saber sobre ela, entendendo-se como uma língua que não se presta à significação, mas, antes, à satisfação pulsional. Isso fala, e isso fala dele a tal ponto que, ainda que ele não fale, ele é falado (Lacan, 1972/1985).

Desse modo, Lacan remete à satisfação pulsional salientando que:

O universo é uma flor de retórica. Este eco literário poderia talvez ajudar a compreender que o eu pode ser também uma flor de retórica, que brota do vaso do princípio do prazer, que Freud chama Lustprinzip, e que eu defino como o que se satisfaz com o blá-blá-blá. (Lacan, 1972/1985, p.77)

Aqui apontamos para o objeto voz, a voz do Outro primordial. Essa voz que aparece no interjogo da presença e ausência para ele. Sendo objeto para o bebê, a voz é dos outros do Outro a quem é cedida a consistência de seu balbucio (Lefort, 1992). Posto que, mesmo assim, se nada é dito aí, se não faz sentido, pelo menos há algo que aponta para o seu próprio gozo, escutando a si mesmo, "presente lá, no mais íntimo, da subjetividade nascente". (Lefort, 1992, p. 08).

Aquilo que chega aos ouvidos do bebê fará borda, cavará o vazio da voz, marcará todo o corpo do pequeno vivente, invocando-o a advir como sujeito pela fala. A ausência de sentido na voz do Outro primordial é que seduz o bebê por meio de uma continuidade musical. Como ressalta Quignard (2007, citado por Martins, Ottavi, Tanguy, \& Bernard, 2014, p. 84): “a criança se fará na 'borda' dos lábios de sua mãe', onde a palavra faltava, cavidade onde a voz ensurdece".

$\mathrm{Na}$ realidade, a pura continuidade está sempre agindo no cerne da fala. Essa continuidade que é produzida pela voz do Outro primordial e que suprime sua fala, com a qual o infans foi confrontado, e, da mesma forma, a pura continuidade do grito do infans, na qual a tendência é abolir a descontinuidade ao transmitir a inteligibilidade do sentido (Vivès, 2009).

O que se espera diante dessa continuidade é que, para advir, o sujeito deverá poder se tornar surdo, um ponto de surdez. Desse modo, ele deverá poder permanecer surdo ao canto da sereia, o Outro primordial, absoluto, do gozo, para ouvir somente o canto da poetisa que o convida a se advir. Lefort (1992) traz a questão da voz como um objeto (a) quando ela só se concilia ao sujeito do significante quando ela perde toda a sua substancialidade e se centra em um vazio. Dessa forma, o grito porta outra função, que não é a do apelo nem o balbucio do gozo, mas de fazer calar o Outro. Assim, nos referenda Lefort (1992, p. 05) que o grito pode se impor numa intensidade tamanha e "esvaziar o objeto voz que lhe chega e sobre o qual ele antecipa os significantes S1 de seu gozo".

Vivès (2009) assevera que o grito como tal só se transformará em apelo por meio da resposta da voz do Outro, na qual se inscreve seu desejo: "o que você quer que eu queira de você?" (p. 335). A partir disso, há uma invocação ao sujeito, ele é chamado a ser. Desse modo, consideramo-lo não como um produto natural ou determinado biologicamente pelo que lhe constitui enquanto matéria, mas apontamos para a voz do Outro que o convoca, que o chama a ser. Para que ele exista, é preciso que o Outro o chame, seja através do apelo, seja pelo simples fato de nominar.

O Outro, personificado nos pequenos outros que cuidam da criança, tomam o grito da criança como o apelo e o abarcam no âmbito de uma demanda, pois supõem um sujeito naquele onde a linguagem ainda está se formalizando. Assim, "pela invocação do Outro, o significante entra no real e produz o sujeito enquanto efeito de significação, à guisa de resposta. Com a resposta do Outro, o grito puro [pur] se tornará grito para [pour]" (Vivès, 2009, p. 335). Desse modo, apreendemos que há, na realidade, uma natureza outra, que não essa associada entre o grito e a pura necessidade. Assinala Lefort (1992, p. 06) que:

A comunicação se impõe, portanto, pela mais banal observação em relação à necessidade da criança que motiva seu grito e que, desse grito, faz apelo pela resposta do outro nutriz, isto é, transforma esse grito em significante, significante da demanda que avança sobre o objeto da necessidade. 
A entrada do infans no mundo linguageiro pressupõe o mal-entendido que esse chamado ou apelo carrega de uma nominação "não-toda" (Lacan, 1980), ou que não completa e se fecha de sentido, posto que a convocação do sujeito, ao mesmo tempo, põe-no ensurdecido para não se emudecer.

Abordando de outro modo, a voz do Outro é referida como aquela que invoca o sujeito, sua fala o convoca. É despojandose de seu grito, que o infans pode, ao mesmo tempo, perder e encontrar a sua voz. Tal como Lacan (1963/2005) nos assevera, a voz é o real do corpo que o sujeito aceita perder para falar. Situando essa relação com a voz do Outro como objeto caído do Outro, Lacan não nos deixa perder a dimensão estrutural, dirigindo a questão para o que é o Outro como sujeito: "com efeito, se a voz é o produto, o objeto caído do órgão da fala, o Outro é o lugar onde isso fala" (Lacan, 1963/2005, p. 71).

Essa voz de que se trata esse ponto referenciado por Lacan é a voz como objeto a. Desse modo, ao ocorrer à queda da voz, enquanto objeto, ela passa a ser perdida nesse ato. Este objeto, a voz, é advinda do Outro, o que permite a Lacan apontar que o lugar do Outro não é somente o do olhar, mas também o é da voz, ou seja, o da invocação, sendo a voz do Outro um "objeto essencial". Lacan, ao referenciar que "o Outro é o lugar onde isso fala", esclarece que o Outro não pode ser confundido com o sujeito que fala no lugar do Outro, nem sequer por sua voz, e remete a um problema que é o do sujeito "anterior à questão" (Lacan, 1963/2005, p. 72). Poderíamos abordar tal posição pensando na operação de alienação.

O homem, para a psicanálise, é definido como um ser falante que está situado no campo simbólico, e é daí que extrai fundamentalmente seu gozo. Porém, para extrair esse gozo, é necessário que haja um corpo, um corpo enquanto orifício. Esse é sempre o ponto limite. Esse gozo está para além do gozo sexual e, quando é sexual, está além do genital. E mesmo quando há relação genital, o gozo está marcado pela impossibilidade de fazer existir o "um" da relação sexual. Afinal, não é o corpo que faz "um", como queria Aristósteles. Para Lacan, só o significante faz "um", e esse é o impasse do sexual.

Resta dizer um pouco mais sobre a teoria do gozo em Lacan: o gozo é o que não serve para nada, não é da ordem do útil nem do necessário. Mais radicalmente, é o excedente que ultrapassa os limites do prazer. Esse imponderável corpo da psicanálise, feito de substância gozosa, é, poderíamos dizer, um corpo que não passa de um fato de discurso (Teixeira, 2013).

Além disso, a linguagem, ao mesmo tempo em que nos afasta de uma sexualidade natural, não fornece nenhuma garantia do que poderia ser um laço entre os sexos, o que nos afasta definitivamente de uma harmonia natural. "Mas o fim da verdade, a verdade verdadeira, é que entre homem e mulher as coisas não caminham bem"(Lacan, 1975, p. 6). Não há um rapport - palavra que Lacan emprega e que significa tanto relação quanto proporção e razão, no sentido lógico-matemático -, pois não há na linguagem um significante que garanta um laço entre os sexos, o que não significa que não pode haver o encontro sexual, obviamente. Ao contrário, a falta instaurada pela linguagem gera o desejo. Lacan (1972/1985) vai dizer, então, que "o que vem em suplência à relação sexual é precisamente o amor", ou seja, que o amor tenta criar imaginariamente esse laço que a linguagem não é capaz de estabelecer.

O que é posto em questão, contudo, em nossa sociedade atual, é que, considerando as vicissitudes as quais as várias modalidades de gozo estão submetidas, vivemos em uma época em que se tornou oficial e tem se consolidado como legítimo um "direito ao gozo" (Zizek, 2008). Aproximando a pontuação trazida por Lacan (1972/1985) acerca de sua "reserva que implica o campo do direito-ao-gozo [...]. Nada força ninguém a gozar, senão o superego. O superego é o imperativo do gozo - Goza!" (p.11), podemos visualizar tais incursões nos micromovimentos sociais de reivindicação de uma legitimidade e reconhecimento políticos dos direitos de usufruto dos gozos orificiais do corpo. O homem, para a psicanálise, é definido como um ser falante que está situado no campo simbólico, sendo é daí que extrai fundamentalmente seu gozo. Porém, para extrair esse gozo, é necessário que haja um corpo, um corpo enquanto orifício.

Tais fenômenos realizam uma aparente dissolução da lógica bijetiva do falo e da diferença sexual por meio de uma nomeação pela diversificação dos tipos de gozo. Contudo não nos é inútil lembrar que "diversidade não equivale à diferença" (Danziato, 2013, p. 276).

O autor ainda aponta que essas formas pelas quais essas incursões sobre o gozo podem se limitar a uma "tipologia" social, que é "típica do laço social entre os sujeitos afetados pelas condições discursivas atuais, e que não seria difícil reencontrar intocada a tradicional "diferença sexual" como uma invariante estrutural no drama da sexuação desses sujeitos (Danziato, 2013, p. 277).

Assim, propomo-nos a pensar nos efeitos dessas modulações discursivas para a posição do sujeito e para a função fálica. Como nos aponta Danziato (2013), estaríamos considerando a possibilidade de danos aos balizamentos da estrutura? Ou estaríamos diante de uma torção pontual, como efeito do excesso das reivindicações do gozo de outras ordens que não o gozo fálico-sexual? De qualquer forma, fazer questão se mostra bem mais lógico do que respondê-la, assim como o movimento que a própria práxis da psicanálise nos aponta.

\section{Psicanálise, Gênero e a Não Relação Sexual}

Na pós-modernidade, deparamo-nos com a ditadura do mais-de-gozar, que, segundo Miller (2012), "devasta a natureza, faz romper os casamentos, dispersa a família, remaneja o corpo" (p.1). Esse ponto de real irredutível que encontramos na 
desordem evidencia que não há relação entre os sexos que se coloque como modelo para todos (Laurent, 2010b).

No esteio da lógica lacaniana de que a diferença entre os sexos "não cessa de não se escrever" abre-se à contingência dos encontros de gozo e à proliferação de normas; e, como tal, reporta-se a novas relações e construções sociais da contemporaneidade (Assef, 2013). Assim, na interseção entre cultura e subjetividade, cada civilização busca ordenar os modos de gozar (Torres, 2013).

Nessa perspectiva, inserem-se os movimentos feministas e suas teorias do que chamamos de estudos de gênero. Estes se constituem, segundo Butler (2003), como uma tentativa de desenvolver uma linguagem capaz de representar as mulheres e de promover sua visibilidade política. Essa questão torna-se crucial para as feministas por considerarem que "os domínios da "representação" política e linguística estabeleceram a priori o critério segundo o qual os próprios sujeitos são formados, com o resultado de a representação só se estender ao que pode ser reconhecido como sujeito" (Butler, 2003, p.18). Com isso, ocorre uma tentativa de constituir, discursivamente, o sujeito feminista.

Ao observar a dificuldade que os sujeitos encontram para se identificarem às normas de gênero e estarem em conformidade com os ideais socialmente estabelecidos, Butler (2003) defende que não é a biologia, mas, antes, a cultura que se torna o destino. Para ela, mulher é um termo em processo, é uma prática discursiva que se encontra sujeita a interpretações e ressignificações.

Podemos dizer que a teoria de gênero retoma e atualiza o enigma da sexualidade ao questionar os binarismos homem/ mulher e heterossexual/homossexual. Ainda além de toda eleição, se introduz o caso a caso, cabendo a cada um inventar sua resposta. Seguindo essa tendência contemporânea, encontramos sujeitos que parecem optar pelo sexo e gênero fluido (Mattos, 2016). Assim, apoiados na afirmação de que meu corpo é meu,

alguns evitam, adiam ou rejeitam a posição feminina ou masculina, oscilando de identidade sexual e na escolha do parceiro. Com aparência andróginas, transitam entre parcerias hetero e homossexuais, travestem-se ou realizam mudanças transexuais, outros declaram-se assexuados ou vivem sem relação com um outro corpo, mas com alguns gadgets. (Mattos, 2016, p.117-118)

Vale ressaltar que gênero não é um termo utilizado por Freud ou por Lacan e, muito menos, um conceito da psicanálise. Segundo Ceccarelli (2010), seu emprego entre os psicanalistas tem provocado polêmicas, sendo algo bem recente e restrito na terminologia psicanalítica brasileira. Para o campo analítico, o que está em questão não é a identificação imaginária a um determinado gênero, mas a posição de objeto frente ao Outro e como isso se insere na fantasia inconsciente de cada sujeito, possibilitando, assim, a identificação sexual e a escolha de objeto (Lutterbach, 2016).

Sobre as dificuldades em estabelecer uma relação direta entre sexo e gênero, esse mesmo autor ressalta que os sujeitos transexuais e os intersexuais (ou pseudo-hermafroditismo) "nos ensinam sobre a sexuação em geral e sobre as relações entre o corpo como objeto estrangeiro ao $\mathrm{Eu}(\mathrm{Ich})$, além de colocarem importantes questões sobre a heterogeneidade daquilo que é da ordem do organismo e o que é do subjetivo" (p.277).

Torna-se, portanto, necessário repensar os conceitos de normalidade e o de patologia, na medida em que são as referências simbólicas que estabelecem o que nomeamos culturalmente como gênero. É preciso ressaltar que a assunção subjetiva do sexo não é uma questão específica aos sujeitos trans; ou melhor dizendo, todo ser humano, independente da biologia, terá que tornar-se subjetivamente homem ou mulher (Ceccarelli, 2010).

Embora seja legítimo abordarmos a temática do gênero a partir das normas de gênero, política e sociologia, não podemos desconsiderar que são representados, encarnados em função de escolhas dos sujeitos (Leguil, 2016), ou seja, "o gênero é algo que é buscado pelo sujeito na tentativa de ir ao encontro de seu ser, sem que nunca possa alcançá-lo completamente" (Santos, 2016, p.15).

Assim, a identidade se constitui como um processo identificatório, um arranjo singular para alçar ao que chamamos de gênero. A esse propósito, Freud (1925/1996d) já afirmava que:

todos os indivíduos humanos, em resultado de sua disposição bissexual e da herança cruzada, combinam em si características tanto masculinas quanto femininas, de maneira que a masculinidade e a feminilidade puras permanecem sendo construções teóricas de conteúdo incerto. (Freud, 1925/1996d, p. 286)

O que nos interessa particularmente é a concepção de que, ao haver uma diferenciação entre o masculino e o feminino, esta não pode ser localizável, cabendo a cada um se situar de um lado ou de outro a partir de um arranjo singular que se constitui como uma mistura (c. Somados a isso, os avanços científicos alteram a relação que se estabelece com o corpo e com o gênero, possibilitando que a mudança de sexo torne-se, além de uma possibilidade, um direito.

Nessa perspectiva, embora seja relevante a afirmação da identidade e da diversidade sexual, não podemos desconsiderar o modo como cada sujeito tem seu corpo afetado pela diferença dos sexos e que a desigualdade não se reduz às diferenças genitais 
ou às segregações sociais (Laia, 2013). Torna-se necessário distinguirmos sexualidade e identidade sexual, na medida em que a sexualidade refere-se ao desejo e a escolha sexual e, por sua vez, o processo de sexuação à identidade (Ansermet, 2015).

Segundo Lacan (1974/2003), a sexualidade faz "furo no real" (p.558), não existindo ninguém que escape ileso às dificuldades introduzidas por esse furo. E, como não há uma fórmula pronta para lidar com isso, as discussões de gênero e as leis que tentam regulamentar essa questão buscam estabelecer uma adequação entre anatomia e o que cada um pode dizer de sua própria identidade de gênero sem conseguir, entretanto, resolver os embaraços dos sujeitos com a coisa sexual.

As palavras não são suficientes para nomear a "coisa sexual" porque naquilo que se diz vai se intrometer uma substância que Lacan chamou "gozo" e que perturba tanto os corpos quanto as palavras, como as articulações entre eles porque se impõe desde um real, um inominável, que é sem lei. (Laia, 2013, p.323, tradução nossa)

E, a esse respeito, com a Lei de Identidade de Gênero, o nomear-se "homem" ou "mulher", independente da anatomia, passa a ter um reconhecimento e um sentido frente ao mal-entendido do sexual. Entretanto o gozo que agita os corpos e o faz falar permanece, segundo Laia (2013), como um ponto de opacidade, de radical fora de sentido.

Desse modo, contrariando o axioma "a anatomia é o destino", podemos afirmar que é, antes, um enigma do real que convoca à simbolização. Nesse contexto, a clínica de orientação lacaniana insere-se como uma possibilidade de acolhimento e de dar voz (Laia, 2013) aos arranjos singulares que cada sujeito inventa para lidar com o sexual e seus impasses.

Frente ao inassimilável, encontramos os semblantes que aprisionam no que é da ordem da família, dos papéis sociais (gênero) e da multiplicidade prêt-à-porter fantasmática do gozo, produzindo incessantemente sintomas a partir do real que transborda (Laurent, 2010a). Nessa direção, é necessário destacar que a prática psicanalítica visa não a convergência entre identidade de gênero e anatomia, mas, antes, a realidade sexual do inconsciente e sua dimensão sintomática.

Nesta práxis, o que o sujeito encontra na psicanálise é sua solidão e seu exílio. Segundo Miller (2013) "uma análise começa por aí, pelo Um sozinho, quando alguém não tem mais remédio que se confessar exilado, deslocado, indisposto, em desequilíbrio no seio do discurso do Outro".

Ao pensar o gênero no singular, o gênero de Um sozinho, a teoria lacaniana se ocupa dos distintos modos pelo qual se busca nomear o real da sexualidade, não se restringindo à diferença anatômica, às identidades ou mesmo ao campo das identificações. Em outras palavras, no campo do sexual, Lacan rompe com a dimensão da anatomia ao localizar a questão de gênero na interface do desejo e gozo, falta-a-ser e pulsão, ato e não relação sexual (Leguil, 2016).

Nessa direção, Lacan introduz, ao final do seu ensino, a teoria da sexuação, que se distingue do conceito de gênero, na medida em que concebe as identidades de gozo articuladas ao campo do simbólico e do real, e não mais ao imaginário. Como sexuação compreende-se o uso particular que cada falasser faz da castração.

Assim, o que está em questão são as posições de gozo, a distinção entre o gozo fálico e o gozo Outro, gozo esse suplementar e relativo ao enigma do feminino. Com isso, qualquer um pode se alojar numa ou outra posição (gozo suplementar ou fálico) frente ao real do sexo.

Ao introduzir a pluralização do gozo, a sexualidade passa a ser abordada a partir das coordenadas do singular. Nesse sentido, François Ansermet (2015) argumenta que a lógica da subjetivação orienta a eleição do tipo de gozo, distinguindo diferentes dimensões que se sobrepõem, as quais são concebidas da seguinte forma: no campo imaginário, a identidade; no simbólico, a nomeação e a filiação; na ordem do real, a eleição entre diferentes modos de gozo (entre um gozo fálico e um gozo Outro; entre um gozo transparente, que é marcado pelo significante, e um gozo opaco).

Assim, retomando a temática da intersexualidade e transexualidade, podemos defender que a clínica da eleição do sexo encontra-se no mais além do campo da identificação, no qual não estão em questão as categorizações, mas o desejo, a procriação, a sexualidade e o modo de gozo (Ansermet, 2015).

\section{Considerações Finais}

Para finalizar, é preciso dizer que permanecemos sem resposta sobre a diferença entre os sexos, pois não sabemos com clareza como ser uma mulher ou como ser um homem. Assim, cada falasser se situa, de modo imprevisível, nos campos discursivos do feminino e do masculino. E, nesse sentido, as fórmulas da sexuação nos possibilitam uma aproximação entre a psicanálise e a teoria de gênero, tornando nosso discurso permeável à bricolagem singular de cada falasser, às soluções que cada um inventa ao se deparar com a não relação sexual.

A esse respeito, podemos inferir que o metamorfosear a diferença entre os sexos se configura como uma invenção particular para lidar com as questões relativas à origem e à morte (Ansermet, 2015). Formas contemporâneas de lidar com o fato de ter nascido em um determinado tempo e com um determinado corpo configurando-se como nova tessitura frente à questão do ser. 


\section{Referências}

Ansermet, F. (2015). Escolher seu sexo: Usos contemporâneos da diferença dos sexos. In Latusa: Um corpo que nasce (pp. 23-35). Rio de Janeiro: EBP Editora.

Assef, J. (2013). De qué sexuación puede uno fiarse? La identidad de género a partir de dos modelos del cine contemporâneo. In M. Torres, G. Schnitzer, A. Antuña \& S. Peidro (Comp.), Transformaciones: ley, diversidad, sexuación (p. 373-380). Buenos Aires: Gramma.

Butler, J. (2003). Problemas de gênero: Feminismo e subversão da identidade. Rio de Janeiro: Civilização Brasileira.

Ceccarelli, P. R. (2010). Psicanálise, sexo e gênero: Algumas reflexões. In C. Rial, J. Pedro \& S. Arende (Orgs.), Diversidades: Dimensões de Gênero e sexualidade (pp.269-285). Florianópolis: Ed. Mulheres. Link

Danziato, L. (2013). A posição do falo e a diferença sexual na adolescência contemporânea. Revista Topos, 13(13), 275-282.

Dias, E. A. (2007). Amor des-medido: A sexualidade feminina, entre o desejo e o gozo. Psicologia Hospitalar, 5(1), 60-72. Link

Freud, S. (1996a). Projeto para uma psicologia científica. In Edição Standard Brasileira das Obras Psicológicas Completas de Sigmund Freud (Vol. 1, pp.335-454). Rio de Janeiro: Imago. (Originalmente publicado em 1895)

Freud, S. (1996b). Conferências Introdutórias da Psicanálise. Conferência XXI. O desenvolvimento da libido e as organizações sexuais. In Edição Brasileira das Obras Psicológicas Completas de Sigmund Freud (Vol. 13, pp. 324338). Rio de Janeiro: Imago. (Originalmente publicado em 1917)

Freud, S. (1996c). O Eu e o ID. In Edição Brasileira das Obras Psicológicas Completas de Sigmund Freud (Vol.16, pp. 1392). Rio de Janeiro: Imago. (Originalmente publicado em 1923)

Freud, S. (1996d). Algumas consequências da distinção anatômica entre os sexos. In Edição Brasileira das Obras Psicológicas Completas de Sigmund Freud (Vol.19, pp. 271-286). Rio de Janeiro: Imago. (Originalmente publicado em 1925)

Lacan, J. (1980). "Le malentendu". O mal-entendido no corpo. Lição de 10 de junho de 1980 do Seminário Dissolução. In Ornicar? (n. 22/23). Bulletin périodique du Champ Freudien. Paris: Lyse/Seuil, (pp. 11-14).

Lacan, J. (1985). O Seminário, livro 20: Mais, ainda. Rio de Janeiro: Jorge Zahar. (Originalmente publicado em 1972)

Lacan, J. (2003). Prefácio a O despertar da primavera. In Outros Escritos (pp. 557-559). Rio de Janeiro: Jorge Zahar. (Originalmente publicado em 1974)

Lacan, J. (2005). Introdução aos Nomes-do-Pai. In Nomes-do-Pai (pp. 55-87). Rio de Janeiro: Jorge Zahar. (Originalmente publicado em 1963)

Lacan, J. (2007). O Seminário, Livro 23: O sinthoma. Rio de Janeiro: Jorge Zahar. (Originalmente publicado em 19751976)

Lacan, J. (2008). O Seminário, Livro 16: De um Outro ao outro. Rio de Janeiro: Jorge Zahar. (Originalmente publicado em 1968-1969)

Laia, S. (2013). Identidad, diversidad y diferencia de los sexos. In: M. Torres, G. Schnitzer, A. Antuña \& S. Peidro (Comp.), Transformaciones: Ley, diversidad, sexuación (pp. 311-323). Buenos Aires: Gramma.

Laurent, É. (2010a). Butler y Gender. In El goce sin rosto: Psicoanálisis y política de las identidades (pp.157-163). Buenos Aires: Tres Haches. 
Laurent, É. (2010b). Siglo XXI: No relación globalizada e igualdad de términos. In El goce sin rosto: psicoanálisis y política de las identidades (pp.178-185). Buenos Aires: Tres Haches.

Lefort, R. (1992). De lalangue a l'Autre ou de la jouissance préalable du Un du $\mathrm{S}_{1}$ au $\mathrm{S}_{2}$ de l'Autre. In: L'Autre du bébé. Séries de la Découverte Freudienne (pp. 05-10). Toulouse: Presses Universitaire du Mirail.

Leguil, C. (2016). O ser e o gênero: Homem/mulher depois de Lacan. Belo Horizonte: EBP Editora.

Leite, M. P. (2003). A sexualidade revisitada por Lacan: Novos fundamentos da psicanálise (mimeografado). São Paulo.

Lutterbach, A. L. (2016). Apresentação. In: C. Leguil, O ser e o gênero: homem/mulher depois de Lacan (pp.11-12). Belo Horizonte: EBP Editora.

Martins, C. M., Ottavi, L., Tanguy, C., \& Bernard, D. (2014). A marca do desejo parental. Arquivos Brasileiros de Psicologia, 66 (3), 74-88. Link

Mattos, C. P. (2016). Quais os impasses e soluções do jovem para a sintomatização do sexual, hoje? Curinga: Uma nova juventude, (42), 115-130.

Miller, J.-A. (2012). Uma fantasia. Conferência de abertura do VIII Congresso da Associação Mundial de Psicanálise. Link

Miller, J.-A. (2013). Falar com o corpo. Conclusão do PIPOL5. In: Textos do VI ENAPOL: VI Encontro Americano de Psicanálise da Orientação Lacaniana (pp.6-10). Link

Santos, A. (2016). Prefácio. In C. Leguil, O ser e o gênero: Homem/mulher depois de Lacan (pp.13-20). Belo Horizonte: EBP Editora.

Soler, C. (2012). Lacan, o inconsciente reinventado (P. Abreu, Trad.). Rio de Janeiro: Cia. de Freud.

Souza, L. C. M. (2013). Do corpo verbal ao corpo audiovisual: Os percursos do corpo significante na obra de Michel Pêcheux e Édipo linguageiro. Revista Eletrônica de Estudos do Discurso e do Corpo, 2(1), 52-76. Link

Teixeira, M. C. (2013). Os transexuais e o sexo para chamar de seu. Link

Teixeira, M. R. (2013). Amor, desejo e gozo na contemporaneidade. Link

Torres, M. (2013). Presentación. In M. Torres, G. Schnitzer, A. Antuña \& S. Peidro (Comp.), Transformaciones: Ley, diversidad, sexuación (pp. 9-10). Buenos Aires: Gramma.

Vivès, J.-M. (2009). Para introduzir a questão da pulsão invocante. Revista Latinoamericana de Psicopatologia Fundamental, 12(2). 329-341. Link

Zizek, S. (2008). Visão em paralaxe. Rio de Janeiro: Boitempo. 


\section{Como citar:}

Cruz, S. V. O., \& Fontenele, A. S. (2020). Sexualidade, Corpo e Psicanálise. Revista Subjetividades, 20(3), e8756. http://doi. org/10.5020/23590777.rs.v20i3.e8756

\section{Endereço para correspondência}

Shimênia Vieira de Oliveira Cruz

E-mail:shimeniax@gmail.com

Alessia Silva Fontenele

E-mail: alessia.fontenele@univasf.edu.br 